\title{
Benchmark 3D: CeVe-DDFV, a Discrete Duality Scheme with Cell/Vertex Unknowns.
}

Yves Coudière and Charles Pierre

\begin{abstract}
This paper presents numerical results for a 3D Cell and Vertex centered DDFV scheme. The method applies to very general 3D meshes including non conformal ones. Its construction and implementation are presented.
\end{abstract}

Key words: finite volume, discrete duality, gradient reconstruction MSC2010: 65-06, 65N08, 65N12

\section{Presentation of the scheme}

\subsection{General presentation of DDFV methods}

"Discrete Duality" Finite Volumes (DDFV) schemes have been specifically designed for anisotropic and/or heterogeneous diffusion problems working on general meshes: distorted, non-conformal and locally refined. They first were introduced in 2D independently by Hermeline [9, 10] and Domelevo and Omnès [8], though the key ideas already appear in the work of Nicolaides [14].

As originally defined in [8], a 2D DDFV scheme consists in associating a second mesh (the dual mesh) to the original (primal) mesh by building dual cells around each (primal) mesh vertex. Cell and vertex centered scalar data are associated to this double mesh framework (one data per primal and dual cell), whereas a vector data consists in one vector per (primal) mesh edge. To a scalar data is associated a discrete gradient that is a vector data. A gradient reconstruction method is used

Yves Coudière

LMJL, Université de Nantes, France, e-mail: Yves. Coudiere@univ-nantes.fr

Charles Pierre

LMA, Université de Pau et des pays de l'Adour, France, e-mail: charles.pierre@ univ-pau.fr 
to define this discrete gradient: precisely using the diamond method [6]. A discrete divergence acts on vector data by averaging their normal component on the primal and dual cell boundaries, which procedure is classical for finite volume methods. The key feature is a duality property between the discrete gradient and the discrete divergence operators of Green formula type.

Extensions of $D D F V$ schemes to 3D [15, 11, 12, 2, 3, 1, 3] are of two types.

$\boldsymbol{C V}$-DDFV. The original 2D double mesh framework is conserved, dual cells are built around the primal mesh vertices and scalar data consist in a double set of unknowns associated with the (primal) mesh cells and vertices.

CeVeFE-DDFV. Recently Coudière and Hubert $[4,3]$ modified the 2D framework by considering a third mesh (triple mesh method), with unknowns associated with cells, faces, edges and vertices of the primal mesh.

The method considered here is of $C V$-DDFV type, $C V$ holding for Cell and Vertex centered. Two versions have been developed so far.

(A) A first 3D construction was introduced by Pierre in [15] for anisotropic and/or heterogeneous diffusion problems. The dual cells here do not form a mesh in the classical sense: they recover the domain twice.

(B) A second version, independently introduced by Hermeline [12] and Andreianov $\&$ al. $[2,1]$ differs from the previous one by the dual cell definition that here form a partition of $\Omega$.

For both versions, in presence of heterogeneity, auxiliary (locally eliminated) data are added relatively to faces, as presented in $[5,12]$. In case of complex meshes, involving face shapes other than triangles or quadrangles, this local elimination procedure is made difficult enforcing to consider auxiliary data as real unknowns inside the algorithm, which drastically increases the problem size.

We first emphasize the similarities between $(A)$ and $(B)$. These two versions are based on the same definition of the discrete gradient. They also induce comparable discrete duality properties. Indeed, after a careful examination of these duality properties in [15] and in [2] it turns out that they do involve exactly the same stiffness and mass matrices. As a result, between these two versions, only the averaging of the source terms on the dual cells will differ.

In this paper, version $(A)$ will be considered without auxiliary data on the mesh faces. The fifth test case, including heterogeneity and thus necessitating these auxiliary unknowns per face center, will not be treated here because of a lack of time.

\subsection{CV-DDFV version (A), discrete duality}

Let the domain $\Omega \subset \mathbb{R}^{3}$ be a connected open subset, its boundary is assumed to be polyhedral. Let $\mathscr{M}$ be a (general) mesh of $\Omega$, possibly non conformal, and whose (primal) cells (resp. faces) are general polyhedral (resp. polygonal). The set of cells, faces and vertices of $\mathscr{M}$ are respectively denoted $\mathscr{C}, \mathscr{F}$ and $\mathscr{V}$. To any vertex $v \in \mathscr{V}$ 
is associated a dual cell $v^{\star}$ and to any face $f \in \mathscr{F}$ is associated a diamond cell $D_{f}$. Diamond cells form a partition of $\Omega$, whereas dual cells intersect and recover $\Omega$ exactly twice.

A vector data is a piecewise constant vector function on the diamond cells. A scalar data is provided by one scalar per cell and per vertex of $\mathscr{M}$. The space of vector data is denoted $\mathbb{Q}_{h}$ and the space of scalar data $\mathbb{F}_{h}$. A discrete function is obtained by supplementing a scalar data with one scalar data per boundary face. The space of discrete functions is denoted $\mathbb{U}_{h}$. As developed in Sec. 1.3, $u_{h} \in \mathbb{U}_{h}$ will be interpreted as a function defined on the diamond cell boundaries:

$$
\partial \mathscr{D}:=\bigcup_{f \in \mathscr{F}} \partial D_{f}, \quad u_{h}: \partial \mathscr{D} \longrightarrow \mathbb{R}
$$

that moreover is continuous and piecewise affine on the diamond cell faces.

Two discrete operators will be defined, $\nabla_{h}: \mathbb{U}_{h} \longrightarrow \mathbb{Q}_{h}$ and $\operatorname{div}_{h}: \mathbb{Q}_{h} \longrightarrow \mathbb{F}_{h}$. that satisfy the discrete duality property (see [15])

$$
\int_{\Omega} \nabla_{h} u_{h} \cdot \mathbf{q}_{h} d x=-\left\langle\left\langle u_{h}, \operatorname{div}_{h} \mathbf{q}_{h}\right\rangle\right\rangle+\int_{\partial \Omega} u_{h} \mathbf{q}_{h} \cdot \mathbf{n} d s
$$

for any functions $u_{h} \in \mathbb{U}_{h}$ and $\mathbf{q}_{h} \in \mathbb{Q}_{h}$, with $\mathbf{n}$ the unit normal on $\partial \Omega$ pointing outside $\Omega$, and the pairing:

$$
\left\langle\left\langle u_{h}, \operatorname{div}_{h} \mathbf{q}_{h}\right\rangle\right\rangle=\frac{1}{3} \sum_{c \in \mathscr{C}} u_{c} \operatorname{div}_{c} \mathbf{q}_{h}|c|+\frac{1}{3} \sum_{v \in \mathscr{V}} u_{v} \operatorname{div}_{v} \mathbf{q}_{h}\left|v^{\star}\right| .
$$

Here, $|c|$ and $\left|v^{\star}\right|$ are the volumes of the primal and dual cells $c$ and $v^{\star}, u_{c}$ and $\operatorname{div}_{c} \mathbf{q}_{h}$ are the values associated to the cell $c$ of the two scalar data $u_{h}$ and $\operatorname{div}_{h} \mathbf{q}_{h}$, and similarly $u_{v}$ and $\operatorname{div}_{v} \mathbf{q}_{h}$ are the values associated to the vertex $v$ of the two scalar data $u_{h}$ and $\operatorname{div}_{h} \mathbf{q}_{h}$.

In (2) the two integrals are well defined. The first integral is an $L^{2}$ product on $\Omega$ since both $\mathbf{q}_{h}$ and $\nabla_{h} u_{h}$ are piecewise constant vector functions on the diamond cells. The second integral is an $L^{2}$ product on $\partial \Omega: \mathbf{q}_{h}$ is piecewise constant on the boundary faces and its normal component $\mathbf{q}_{h} \cdot \mathbf{n}$ also, moreover $\partial \Omega \subset \partial \mathscr{D}$ defined in (1) and so $u_{h}$ has a restriction to $\partial \Omega$ that is continuous.

\subsection{Dual and diamond cells}

A center $x_{c}$ (resp. $x_{f}$ ) is associated to each cell $c \in \mathscr{C}$ (resp. $\left.f \in \mathscr{F}\right)$.

Diamond cells. Let $f \in \mathscr{F}$. In case $f \not \subset \partial \Omega$ then $f$ is the interface between two cells $c_{1}, c_{2} \in \mathscr{C}: f=\overline{c_{1}} \cap \overline{c_{2}}$. Denoting $x_{i}$ the center of $c_{i}$, then $D_{f}$ is the union of the two pyramids with apex $x_{i}$ and with base $f$ as depicted on Fig. 1. In case $f \subset \partial \Omega$, then $f=\partial \Omega \cap c$ for one cell $c \in \mathscr{C}$. In this case $D_{f}$ is the pyramid with apex $x_{c}$ and base $f$. Still in this cases, $f$ can be considered as a degenerated (flat) 
pyramid of apex its own center $x_{f}$ and base $f$. Thus, in all cases, $D_{f}$ is the union of two pyramids, and its boundary can be partitioned into triangles. The vertices of these triangles either are: cell centers, vertices or boundary face centers of $\mathscr{M}$. As a result providing a scalar value to each cell, vertex and boundary face of $\mathscr{M}$ defines a unique continuous piecewise affine function $u_{h}: \partial \mathscr{D} \mapsto \mathbb{R}$, with $\partial \mathscr{D}$ defined in (1). This is precisely the lift from the discrete function in $\mathbb{U}_{h}$ presented in Sec. 1.2 into continuous piecewise affine functions on $\partial \mathscr{D}$ in (1).

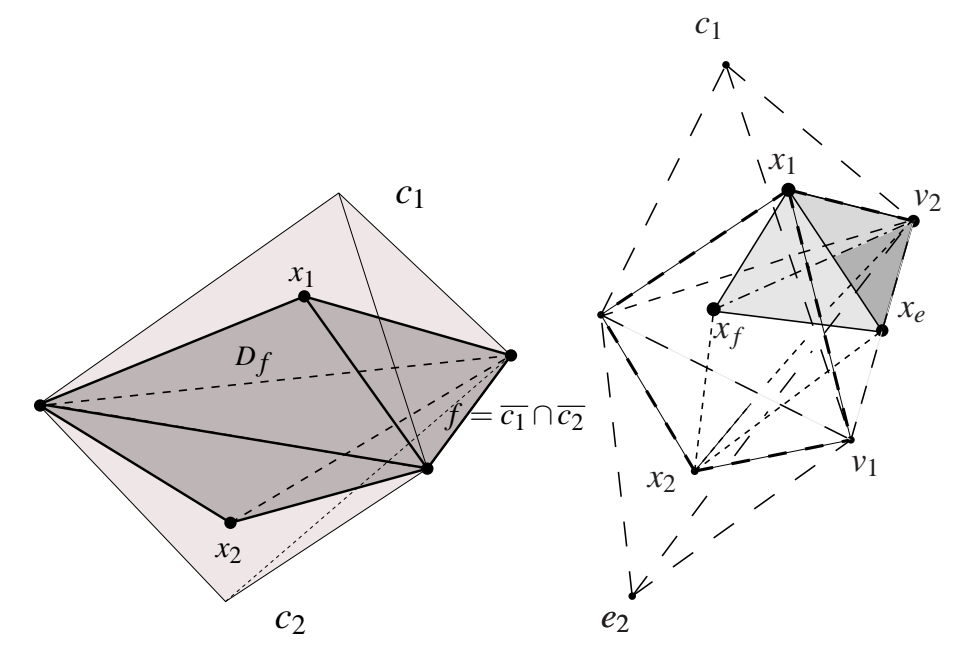

Fig. 1 Left: diamond cell for an internal triangular face $f$. Right: dual cell construction.

Dual cells. Let $v \in \mathscr{V}$ and consider a cell $c \in \mathscr{C}$ and a face $f \in \mathscr{F}$ so that $v$ is a vertex of $f$ and $f$ is a face of $c$. This configuration is denoted by $v \prec f \prec c$. To a triple $(v, f, c)$ so that $v \prec f \prec c$ is associated an element $T_{v, f, c}$. The dual cell $v^{\star}$ then is defined as $v^{\star}=\bigcup_{f, c: v \prec f \prec c} T_{v, f, c}$. Let us eventually define the element $T_{v, f, c}$, as depicted on Fig. 1. Introduce $w_{1}$ and $w_{2}$ the two vertices of $f$ such that $\left[v, w_{1}\right]$ and $\left[v, w_{2}\right]$ are two edges of $f$. Then $T_{v, f, c}$ is the union of the two tetrahedra $v x_{c} x_{f} w_{i}$ for $i=1,2$.

As one can see, for a fixed face $f$ and a fixed cell $c$ such that $f \subset \partial c$, considering all elements $T_{v, f, c}$ for all the vertices $v$ of $f$ recovers exactly twice $D_{f} \cap c$. As a result the dual cells recover the whole domain exactly twice: $\sum_{v \in \mathscr{V}}\left|v^{\star}\right|=2|\Omega|$.

\subsection{Discrete operators}

The discrete divergence is classically defined by averaging the normal component of $\mathbf{q}_{h} \in \mathbb{Q}_{h}$ on the primal and dual cells, for all $c \in \mathscr{C}$ and all $v \in \mathscr{V}$ : 


$$
\operatorname{div}_{c} \mathbf{q}_{h}=\frac{1}{|c|} \int_{\partial c} \mathbf{q}_{h} \cdot \mathbf{n} d s, \quad \operatorname{div}_{v} \mathbf{q}_{h}=\frac{1}{\left|v^{\star}\right|} \int_{\partial v^{\star}} \mathbf{q}_{h} \cdot \mathbf{n} d s,
$$

for $\mathbf{n}$ the unit normal on $\partial c\left(\right.$ resp. $\left.\partial v^{\star}\right)$ pointing outside $c\left(\right.$ resp. $\left.v^{\star}\right)$. This definition is well posed since the discontinuity set of $\mathbf{q}_{h} \in \mathbb{Q}_{h}$ has a zero 2-dimensional measure intersection with the primal and dual cell boundaries.

The discrete gradient is defined as follows. Let $u_{h} \in \mathbb{U}_{h}$, for all $f \in \mathscr{F}$ :

$$
\nabla_{f} u_{h}=\frac{1}{\left|D_{f}\right|} \int_{\partial D_{f}} u_{h} \mathbf{n} d s,
$$

where $\nabla_{f} u_{h}$ is the (vector) value of $\nabla_{h} u_{h}$ on $D_{f}$ and for $\mathbf{n}$ the unit normal on $\partial_{D_{f}}$ pointing outside $D_{f}$.

In practice, definition (5) can always be reformulated in terms of data differences as in the 2D case where (see e.g. [7]):

$$
\nabla_{f} u_{h}=\left(u_{c_{1}}-u_{c_{2}}\right) \mathbf{N}_{f}+\left(u_{v_{1}}-u_{v_{2}}\right) \mathbf{M}_{f},
$$

$f$ is a mesh interface (edge), $c_{1}$ and $c_{2}$ the two cells on each side of $f, v_{1}$ and $v_{2}$ the two vertices of $f$ and $\mathbf{N}_{f}, \mathbf{M}_{f}$ two vectors. We refer to [15, 5] for similar expansions in $3 \mathrm{D}$.

\subsection{The scheme}

The linear diffusion problem $-\operatorname{div}(\mathbf{K} \nabla u)=f$ is considered together with a Dirichlet boundary condition $u_{\mid \partial \Omega}=g$. The tensor $\mathbf{K}$ is discretized into $\mathbf{K}_{h}$ by averaging $\mathbf{K}$ on each diamond cells and the source term $f$ is discretized as $f_{h} \in \mathbb{F}_{h}$ by averaging $f$ over each primal and dual cells. The problem reads: find $u_{h} \in \mathbb{U}_{h}$ such that

$$
\begin{gathered}
\forall c \in \mathscr{C}: \operatorname{div}_{c}\left(\mathbf{K}_{h} \nabla_{h} u_{h}\right)=f_{c}, \quad \forall v \in \mathscr{V}, v \notin \partial \Omega: \operatorname{div}_{v}\left(\mathbf{K}_{h} \nabla_{h} u_{h}\right)=f_{v} \\
\forall v \in \mathscr{V}, v \in \partial \Omega: u_{h}(v)=g(v), \quad \forall f \in \mathscr{F}, f \subset \partial \Omega: u_{h}\left(x_{f}\right)=g\left(x_{f}\right),
\end{gathered}
$$

To solve (6) (7), we split $\mathbb{U}_{h}=\mathbb{U}_{h, 0} \oplus \mathbb{B}$ where $\mathbb{U}_{h, 0}$ is the subset of discrete functions equal to zero on $\partial \Omega$. Then $u_{h}$ decomposes as $u_{h}=u_{0}+\tilde{u}$, where $\tilde{u} \in \mathbb{B}$ is uniquely determined by (7). Now $u_{0} \in \mathbb{U}_{h, 0}$ satisfies $-\operatorname{div}_{h}\left(\mathbf{K}_{h} \nabla_{h} u_{0}\right)=f_{h}+$ $\operatorname{div}_{h}\left(\mathbf{K}_{h} \nabla_{h} \tilde{u}\right):=\tilde{f}_{h}$ for all primal cells and all interior vertices. This is a square linear system equivalent with: find $u_{0} \in \mathbb{U}_{h, 0}$ so that for all $v \in \mathbb{U}_{h, 0}$ we have:

$$
-\left\langle\left\langle\operatorname{div}_{h}\left(\mathbf{K}_{h} \nabla_{h} u_{0}\right), v\right\rangle\right\rangle=\left\langle\left\langle\tilde{f}_{h}, v\right\rangle\right\rangle
$$

With the help of the discrete duality property (2) it is also equivalent with finding $u_{0} \in \mathbb{U}_{h, 0}$ so that for all $v \in \mathbb{U}_{h, 0}$ :

$$
\int_{\Omega} \mathbf{K}_{h} \nabla_{h} u_{0} \cdot \nabla_{h} v d x=\left\langle\left\langle\tilde{f}_{h}, v\right\rangle\right\rangle .
$$


In practice, introducing the stiffness matrix $S$ associated to the discrete tensor $\mathbf{K}_{h}$, this problem is rewritten as the square positive symmetric linear system

$$
S U_{0}=\tilde{F}
$$

with $U_{0}$ (resp. $\left.\tilde{F}\right)$ the vector formed by the values of $u_{0}$ (resp. $\tilde{f}_{h}$ ) at the cell centers and interior vertices. The stiffness matrix $S$ has the coefficients $S_{i j}=\int_{\Omega} \mathbf{K}_{h} \nabla_{h} w_{i}$. $\nabla_{h} w_{j} d x$, with $w_{i} \in \mathbb{U}_{h, 0}$ the base function having value 1 at one cell center or interior vertex and 0 everywhere else. This matrix is clearly symmetric and positive.

\section{Numerical results}

The cell centers as well as the face centers are set to their iso-barycenter.

Let us first define the data (source term $f$ and anisotropy tensor $\mathbf{K}$ ) discretization. Primal, dual and diamond cells are partitioned using a single set of tetrahedra of type $E=x_{c} x_{f} v_{1} v_{2}$, with $c \in \mathscr{C}, f$ a face of $c$ and $v_{1}, v_{2}$ two vertices of $f$ forming one of its edges. To form the scalar data $f_{h}, f$ is averaged on the tetrahedra $E$ partitioning each primal and dual cells whereas the discrete tensor $\mathbf{K}_{h}$ is obtained by averaging $\mathbf{K}$ on the tetrahedra $E$ partitioning the diamond cells. Averaging is made by the mean of Gaussian quadrature on each tetrahedra $E$ using a 15 points quadrature formula of order 5, see e.g. [13]. Assembling the discrete source term $f_{h}$ and tensor $\mathbf{K}_{h}$ requires one loop on the mesh faces.

The stiffness matrix $S$ in (8) also is assembled using a loop on the mesh faces. Precisely two base functions $w_{i}$ and $w_{j}$ have a non zero interaction (i.e. $\left.S_{i j}=\int_{\Omega} \mathbf{K}_{h} \nabla_{h} w_{i} \cdot \nabla_{h} w_{j} d x \neq 0\right)$ in case they are associated to two vertices of a same diamond $D_{f}$.

Let us now define the $L^{2}, H^{1}$ and energy errors reported in the following tables as erl2, ergrad and ener respectively. Let $u_{h}$ denote the discrete solution of one of the test case, and $u$ the solution of the associated continuous problem. The discrete function $u_{h}$ is lifted to a function $\bar{u}_{h} \in L^{2}(\Omega)$ as follows. Consider a face $f, u_{h}$ provides a value at each vertex of $D_{f}$ and also at the face center $x_{f}$ in case of a boundary face. In case of an interior face, a supplementary value $u_{f}$ is computed at $x_{f}$ as $u_{f}=\left(\sum_{i=1}^{n} u_{v_{i}}\right) / n$ where the $v_{i}$ are the $n$ vertices of $f$, which definition is consistent since $x_{f}$ is the iso-barycenter of $f$. With these additional values, scalars are available for every vertices of the tetrahedra $E$ that partition $\Omega$ : this defines a unique function $\bar{u}_{h}$ by $P^{1}$ interpolation, which then is continuous piecewise affine on $\Omega$. We define:

$$
\operatorname{erl} 2^{2}=\frac{\int_{\Omega}\left|\bar{u}_{h}-u\right|^{2} d x}{\int_{\Omega}|u|^{2} d x} .
$$

The discrete vector data $\nabla_{h} u_{h}$ is a piecewise constant vector function on the diamond cells. Therefore $\nabla_{h} u_{h}$ is an $L^{2}$ functions on $\Omega$ and the $H^{1}$ and energy errors reported in the following tables are defined as: 


$$
\operatorname{ergrad}^{2}=\frac{\int_{\Omega}\left|\nabla_{h} u_{h}-\nabla u\right|^{2} d x}{\int_{\Omega}|\nabla u|^{2} d x}, \quad \operatorname{ener}^{2}=\frac{\int_{\Omega} K\left(\nabla_{h} u_{h}-\nabla u\right) \cdot\left(\nabla_{h} u_{h}-\nabla u\right)}{\int_{\Omega} K \nabla u \cdot \nabla u d x} .
$$

- Test 1 Mild anisotropy, $u(x, y, z)=1+\sin (\pi x) \sin \left(\pi\left(y+\frac{1}{2}\right)\right) \sin \left(\pi\left(z+\frac{1}{3}\right)\right)$ $\min =0, \max =2$, Tetrahedral meshes

\begin{tabular}{|c|c|c|c|c|c|c|}
\hline $\mathrm{nu}$ & nmat & umin & uemin & umax & uemax & normg \\
\hline 2187 & 21287 & $1.34 \mathrm{E}-02$ & $1.53 \mathrm{E}-02$ & $1.99 \mathrm{E}+00$ & $1.99 \mathrm{E}+00$ & $1.80 \mathrm{E}+00$ \\
\hline 4301 & 44813 & $3.24 \mathrm{E}-03$ & $6.84 \mathrm{E}-03$ & $1.99 \mathrm{E}+00$ & $1.99 \mathrm{E}+00$ & $1.80 \mathrm{E}+00$ \\
\hline 8584 & 94088 & 8.78 & 7.4 & 2.00 & 1.9 & 1.80 \\
\hline 17 & 19507 & $4.74 \mathrm{E}-\mathrm{C}$ & $5.52 \mathrm{E}-$ & 2.0 & 2.0 & +4 \\
\hline 34 & & 5.9 & $1.49 \mathrm{I}$ & $2.00 \mathrm{E}$ & $2.00 \mathrm{E}$ & $1.80 \mathrm{E}+00$ \\
\hline 16 & 85 & $30 \mathrm{E}-03$ & $6.19 \mathrm{E}-\mathrm{C}$ & $2.00 \mathrm{E}+\mathrm{C}$ & $2.00 \mathrm{CT}$ & $1.80 \mathrm{E}+$ \\
\hline
\end{tabular}

\begin{tabular}{|c|ccccccc|}
$\mathrm{i}$ & $\mathrm{nu}$ & erl2 & ratiol2 & ergrad & ratiograd & ener & ratioener \\
\hline 1 & 2187 & $1.39 \mathrm{E}-02$ & - & $1.85 \mathrm{E}-01$ & - & $1.80 \mathrm{E}-01$ & - \\
2 & 4301 & $8.80 \mathrm{E}-03$ & $2.04 \mathrm{E}+00$ & $1.48 \mathrm{E}-01$ & $1.01 \mathrm{E}+00$ & $1.44 \mathrm{E}-01$ & $9.89 \mathrm{E}-01$ \\
3 & 8584 & $5.64 \mathrm{E}-03$ & $1.93 \mathrm{E}+00$ & $1.18 \mathrm{E}-01$ & $9.73 \mathrm{E}-01$ & $1.15 \mathrm{E}-01$ & $9.97 \mathrm{E}-01$ \\
4 & 17102 & $3.61 \mathrm{E}-03$ & $1.94 \mathrm{E}+00$ & $9.36 \mathrm{E}-02$ & $1.01 \mathrm{E}+00$ & $9.10 \mathrm{E}-02$ & $1.01 \mathrm{E}+00$ \\
5 & 34343 & $2.26 \mathrm{E}-03$ & $2.01 \mathrm{E}+00$ & $7.43 \mathrm{E}-02$ & $9.92 \mathrm{E}-01$ & $7.24 \mathrm{E}-02$ & $9.81 \mathrm{E}-01$ \\
6 & 69160 & $1.42 \mathrm{E}-03$ & $2.00 \mathrm{E}+00$ & $5.87 \mathrm{E}-02$ & $1.01 \mathrm{E}+00$ & $5.70 \mathrm{E}-02$ & $1.02 \mathrm{E}+00$ \\
\hline
\end{tabular}

- Test 1 Mild anisotropy, $u(x, y, z)=1+\sin (\pi x) \sin \left(\pi\left(y+\frac{1}{2}\right)\right) \sin \left(\pi\left(z+\frac{1}{3}\right)\right)$ $\min =0, \max =2$, Voronoï meshes

\begin{tabular}{|c|ccccccc|}
$\mathrm{i}$ & nu & nmat & umin & uemin & umax & uemax & normg \\
\hline 1 & 87 & 1433 & $1.23 \mathrm{E}-01$ & $1.79 \mathrm{E}-01$ & $1.91 \mathrm{E}+00$ & $1.85 \mathrm{E}+00$ & $1.80 \mathrm{E}+00$ \\
2 & 235 & 4393 & $6.66 \mathrm{E}-02$ & $2.93 \mathrm{E}-03$ & $1.87 \mathrm{E}+00$ & $2.00 \mathrm{E}+00$ & $1.80 \mathrm{E}+00$ \\
3 & 527 & 10777 & $1.32 \mathrm{E}-02$ & $9.56 \mathrm{E}-03$ & $1.93 \mathrm{E}+00$ & $1.97 \mathrm{E}+00$ & $1.80 \mathrm{E}+00$ \\
4 & 1013 & 21793 & $-1.76 \mathrm{E}-03$ & $4.97 \mathrm{E}-03$ & $1.93 \mathrm{E}+00$ & $2.00 \mathrm{E}+00$ & $1.80 \mathrm{E}+00$ \\
5 & 1776 & 40998 & $5.42 \mathrm{E}-04$ & $4.30 \mathrm{E}-03$ & $1.98 \mathrm{E}+00$ & $1.97 \mathrm{E}+00$ & $1.80 \mathrm{E}+00$ \\
\hline
\end{tabular}

\begin{tabular}{|c|ccccccc|}
$\mathrm{i}$ & $\mathrm{nu}$ & erl2 & ratiol2 & ergrad & ratiograd & ener & ratioener \\
\hline 1 & 87 & $6.19 \mathrm{E}-02$ & - & $4.43 \mathrm{E}-01$ & - & $4.29 \mathrm{E}-01$ & - \\
2 & 235 & $3.36 \mathrm{E}-02$ & $1.85 \mathrm{E}+00$ & $3.37 \mathrm{E}-01$ & $8.28 \mathrm{E}-01$ & $3.29 \mathrm{E}-01$ & $7.96 \mathrm{E}-01$ \\
3 & 527 & $2.10 \mathrm{E}-02$ & $1.74 \mathrm{E}+00$ & $2.55 \mathrm{E}-01$ & $1.03 \mathrm{E}+00$ & $2.49 \mathrm{E}-01$ & $1.04 \mathrm{E}+00$ \\
4 & 1013 & $1.35 \mathrm{E}-02$ & $2.03 \mathrm{E}+00$ & $2.05 \mathrm{E}-01$ & $1.01 \mathrm{E}+00$ & $2.01 \mathrm{E}-01$ & $9.85 \mathrm{E}-01$ \\
5 & 1776 & $9.99 \mathrm{E}-03$ & $1.62 \mathrm{E}+00$ & $1.75 \mathrm{E}-01$ & $8.38 \mathrm{E}-01$ & $1.71 \mathrm{E}-01$ & $8.47 \mathrm{E}-01$ \\
\hline
\end{tabular}


- Test 1 Mild anisotropy, $u(x, y, z)=1+\sin (\pi x) \sin \left(\pi\left(y+\frac{1}{2}\right)\right) \sin \left(\pi\left(z+\frac{1}{3}\right)\right)$ $\min =0, \max =2$, Kershaw meshes

\begin{tabular}{|c|ccccccc|}
$\mathrm{i}$ & $\mathrm{nu}$ & nmat & umin & uemin & umax & uemax & normg \\
\hline 1 & 855 & 13819 & $7.16 \mathrm{E}-02$ & $2.88 \mathrm{E}-02$ & $1.94 \mathrm{E}+00$ & $1.96 \mathrm{E}+00$ & $1.80 \mathrm{E}+00$ \\
2 & 7471 & 138691 & $1.26 \mathrm{E}-02$ & $6.45 \mathrm{E}-03$ & $1.99 \mathrm{E}+00$ & $1.99 \mathrm{E}+00$ & $1.80 \mathrm{E}+00$ \\
3 & 62559 & 1237459 & $1.30 \mathrm{E}-03$ & $1.75 \mathrm{E}-03$ & $2.00 \mathrm{E}+00$ & $2.00 \mathrm{E}+00$ & $1.80 \mathrm{E}+00$ \\
4 & 512191 & 10443763 & $4.61 \mathrm{E}-04$ & $5.45 \mathrm{E}-04$ & $2.00 \mathrm{E}+00$ & $2.00 \mathrm{E}+00$ & $1.80 \mathrm{E}+00$ \\
\hline
\end{tabular}

\begin{tabular}{|c|ccccccc|}
$\mathrm{i}$ & $\mathrm{nu}$ & erl2 & ratiol2 & ergrad & ratiograd & ener & ratioener \\
\hline 1 & 855 & $5.64 \mathrm{E}-02$ & - & $4.57 \mathrm{E}-01$ & - & $4.51 \mathrm{E}-01$ & - \\
2 & 7471 & $1.71 \mathrm{E}-02$ & $1.65 \mathrm{E}+00$ & $1.91 \mathrm{E}-01$ & $1.20 \mathrm{E}+00$ & $1.89 \mathrm{E}-01$ & $1.21 \mathrm{E}+00$ \\
3 & 62559 & $3.45 \mathrm{E}-03$ & $2.26 \mathrm{E}+00$ & $7.74 \mathrm{E}-02$ & $1.28 \mathrm{E}+00$ & $7.67 \mathrm{E}-02$ & $1.27 \mathrm{E}+00$ \\
4 & 512191 & $7.62 \mathrm{E}-04$ & $2.15 \mathrm{E}+00$ & $3.47 \mathrm{E}-02$ & $1.14 \mathrm{E}+00$ & $3.41 \mathrm{E}-02$ & $1.16 \mathrm{E}+00$ \\
\hline
\end{tabular}

- Test 1 Mild anisotropy, $u(x, y, z)=1+\sin (\pi x) \sin \left(\pi\left(y+\frac{1}{2}\right)\right) \sin \left(\pi\left(z+\frac{1}{3}\right)\right)$ $\min =0, \max =2$, Checkerboard meshes

\begin{tabular}{|c|ccccccc|}
$\mathrm{i}$ & $\mathrm{nu}$ & nmat & umin & uemin & umax & uemax & normg \\
\hline 1 & 59 & 703 & $1.46 \mathrm{E}-01$ & $3.41 \mathrm{E}-02$ & $1.86 \mathrm{E}+00$ & $1.97 \mathrm{E}+00$ & $1.80 \mathrm{E}+00$ \\
2 & 599 & 9835 & $3.87 \mathrm{E}-02$ & $8.56 \mathrm{E}-03$ & $1.96 \mathrm{E}+00$ & $1.99 \mathrm{E}+00$ & $1.80 \mathrm{E}+00$ \\
3 & 5423 & 101539 & $9.24 \mathrm{E}-03$ & $2.14 \mathrm{E}-03$ & $1.99 \mathrm{E}+00$ & $2.00 \mathrm{E}+00$ & $1.80 \mathrm{E}+00$ \\
4 & 46175 & 917395 & $2.15 \mathrm{E}-03$ & $5.35 \mathrm{E}-04$ & $2.00 \mathrm{E}+00$ & $2.00 \mathrm{E}+00$ & $1.80 \mathrm{E}+00$ \\
5 & 381119 & 7788403 & $5.01 \mathrm{E}-04$ & $1.34 \mathrm{E}-04$ & $2.00 \mathrm{E}+00$ & $2.00 \mathrm{E}+00$ & $1.80 \mathrm{E}+00$ \\
\hline
\end{tabular}

\begin{tabular}{|c|ccccccc|}
$\mathrm{i}$ & $\mathrm{nu}$ & erl2 & ratiol2 & ergrad & ratiograd & ener & ratioener \\
\hline 1 & 59 & $4.79 \mathrm{E}-02$ & - & $4.01 \mathrm{E}-01$ & - & $3.94 \mathrm{E}-01$ & - \\
2 & 599 & $1.08 \mathrm{E}-02$ & $1.93 \mathrm{E}+00$ & $1.95 \mathrm{E}-01$ & $9.34 \mathrm{E}-01$ & $1.92 \mathrm{E}-01$ & $9.31 \mathrm{E}-01$ \\
3 & 5423 & $2.55 \mathrm{E}-03$ & $1.96 \mathrm{E}+00$ & $9.58 \mathrm{E}-02$ & $9.66 \mathrm{E}-01$ & $9.37 \mathrm{E}-02$ & $9.73 \mathrm{E}-01$ \\
4 & 46175 & $6.27 \mathrm{E}-04$ & $1.96 \mathrm{E}+00$ & $4.75 \mathrm{E}-02$ & $9.83 \mathrm{E}-01$ & $4.63 \mathrm{E}-02$ & $9.89 \mathrm{E}-01$ \\
5 & 381119 & $1.56 \mathrm{E}-04$ & $1.98 \mathrm{E}+00$ & $2.36 \mathrm{E}-02$ & $9.92 \mathrm{E}-01$ & $2.30 \mathrm{E}-02$ & $9.95 \mathrm{E}-01$ \\
\hline
\end{tabular}

- Test 2 Heterogeneous anisotropy,

$u(x, y, z)=x^{3} y^{2} z+x \sin (2 \pi x z) \sin (2 \pi x y) \sin (2 \pi z), \min =-0.862, \max =1.0487$, Prism meshes

\begin{tabular}{|c|ccccccc|}
$\mathrm{i}$ & $\mathrm{nu}$ & nmat & umin & uemin & umax & uemax & normg \\
\hline 1 & 3010 & 64158 & $-8.54 \mathrm{E}-01$ & $-8.41 \mathrm{E}-01$ & $1.00 \mathrm{E}+00$ & $1.00 \mathrm{E}+00$ & $1.71 \mathrm{E}+00$ \\
2 & 24020 & 555528 & $-8.56 \mathrm{E}-01$ & $-8.59 \mathrm{E}-01$ & $1.02 \mathrm{E}+00$ & $1.05 \mathrm{E}+00$ & $1.71 \mathrm{E}+00$ \\
3 & 81030 & 1924098 & $-8.61 \mathrm{E}-01$ & $-8.59 \mathrm{E}-01$ & $1.04 \mathrm{E}+00$ & $1.04 \mathrm{E}+00$ & $1.71 \mathrm{E}+00$ \\
4 & 192040 & 4619868 & $-8.59 \mathrm{E}-01$ & $-8.61 \mathrm{E}-01$ & $1.04 \mathrm{E}+00$ & $1.05 \mathrm{E}+00$ & $1.71 \mathrm{E}+00$ \\
\hline
\end{tabular}




\begin{tabular}{|c|ccccccc|}
$\mathrm{i}$ & $\mathrm{nu}$ & erl2 & ratiol2 & ergrad & ratiograd & ener & ratioener \\
\hline 1 & 3010 & $5.06 \mathrm{E}-02$ & - & $2.45 \mathrm{E}-01$ & - & $2.48 \mathrm{E}-01$ & - \\
2 & 24020 & $1.85 \mathrm{E}-02$ & $1.45 \mathrm{E}+00$ & $1.26 \mathrm{E}-01$ & $9.63 \mathrm{E}-01$ & $1.27 \mathrm{E}-01$ & $9.66 \mathrm{E}-01$ \\
3 & 81030 & $1.46 \mathrm{E}-02$ & $5.90 \mathrm{E}-01$ & $8.51 \mathrm{E}-02$ & $9.63 \mathrm{E}-01$ & $8.59 \mathrm{E}-02$ & $9.66 \mathrm{E}-01$ \\
4 & 192040 & $1.37 \mathrm{E}-02$ & $2.08 \mathrm{E}-01$ & $6.49 \mathrm{E}-02$ & $9.44 \mathrm{E}-01$ & $6.53 \mathrm{E}-02$ & $9.50 \mathrm{E}-01$ \\
\hline
\end{tabular}

- Test 3 Flow on random meshes, $u(x, y, z)=\sin (2 \pi x) \sin (2 \pi y) \sin (2 \pi z)$, $\min =-1, \max =1$, Random meshes

\begin{tabular}{|c|ccccccc|}
$\mathrm{i}$ & $\mathrm{nu}$ & $\mathrm{nmat}$ & $\mathrm{umin}$ & uemin & umax & uemax & normg \\
\hline 1 & 91 & 1063 & $-1.58 \mathrm{E}+00$ & $-9.78 \mathrm{E}-01$ & $1.54 \mathrm{E}+00$ & $9.31 \mathrm{E}-01$ & $3.65 \mathrm{E}+00$ \\
2 & 855 & 13819 & $-1.08 \mathrm{E}+00$ & $-9.94 \mathrm{E}-01$ & $1.12 \mathrm{E}+00$ & $9.82 \mathrm{E}-01$ & $3.57 \mathrm{E}+00$ \\
3 & 7471 & 138691 & $-1.04 \mathrm{E}+00$ & $-9.95 \mathrm{E}-01$ & $1.01 \mathrm{E}+00$ & $9.91 \mathrm{E}-01$ & $3.60 \mathrm{E}+00$ \\
4 & 62559 & 1237459 & $-1.01 \mathrm{E}+00$ & $-9.98 \mathrm{E}-01$ & $1.01 \mathrm{E}+00$ & $9.98 \mathrm{E}-01$ & $3.60 \mathrm{E}+00$ \\
\hline
\end{tabular}

\begin{tabular}{|c|ccccccc|}
$\mathrm{i}$ & $\mathrm{nu}$ & erl2 & ratiol2 & ergrad & ratiograd & ener & ratioener \\
\hline 1 & 91 & $3.06 \mathrm{E}-01$ & - & $5.89 \mathrm{E}-01$ & - & $5.70 \mathrm{E}-01$ & - \\
2 & 855 & $8.29 \mathrm{E}-02$ & $1.75 \mathrm{E}+00$ & $3.14 \mathrm{E}-01$ & $8.56 \mathrm{E}-01$ & $2.87 \mathrm{E}-01$ & $9.21 \mathrm{E}-01$ \\
3 & 7471 & $2.28 \mathrm{E}-02$ & $1.79 \mathrm{E}+00$ & $1.65 \mathrm{E}-01$ & $8.90 \mathrm{E}-01$ & $1.46 \mathrm{E}-01$ & $9.28 \mathrm{E}-01$ \\
4 & 62559 & $6.98 \mathrm{E}-03$ & $1.67 \mathrm{E}+00$ & $8.96 \mathrm{E}-02$ & $8.58 \mathrm{E}-01$ & $7.34 \mathrm{E}-02$ & $9.68 \mathrm{E}-01$ \\
\hline
\end{tabular}

- Test 4 Flow around a well, Well meshes, $\min =0, \max =5.415$

\begin{tabular}{|c|ccccccc|}
$\mathrm{i}$ & $\mathrm{nu}$ & nmat & umin & uemin & umax & uemax & normg \\
\hline 1 & 1482 & 23942 & $4.85 \mathrm{E}-01$ & $-6.02 \mathrm{E}-06$ & $5.32 \mathrm{E}+00$ & $5.42 \mathrm{E}+00$ & $1.62 \mathrm{E}+03$ \\
2 & 3960 & 70872 & $2.71 \mathrm{E}-01$ & $-5.68 \mathrm{E}-06$ & $5.33 \mathrm{E}+00$ & $5.42 \mathrm{E}+00$ & $1.62 \mathrm{E}+03$ \\
3 & 9229 & 173951 & $1.66 \mathrm{E}-01$ & $-5.76 \mathrm{E}-06$ & $5.33 \mathrm{E}+00$ & $5.42 \mathrm{E}+00$ & $1.62 \mathrm{E}+03$ \\
4 & 21156 & 412240 & $1.25 \mathrm{E}-01$ & $-7.39 \mathrm{E}-06$ & $5.33 \mathrm{E}+00$ & $5.42 \mathrm{E}+00$ & $1.62 \mathrm{E}+03$ \\
5 & 44420 & 882520 & $9.37 \mathrm{E}-02$ & $-6.93 \mathrm{E}-06$ & $5.34 \mathrm{E}+00$ & $5.42 \mathrm{E}+00$ & $1.62 \mathrm{E}+03$ \\
6 & 82335 & 1654893 & $7.48 \mathrm{E}-02$ & $-6.94 \mathrm{E}-06$ & $5.35 \mathrm{E}+00$ & $5.42 \mathrm{E}+00$ & $1.62 \mathrm{E}+03$ \\
7 & 145079 & 2937937 & $5.80 \mathrm{E}-02$ & $-8.05 \mathrm{E}-06$ & $5.36 \mathrm{E}+00$ & $5.42 \mathrm{E}+00$ & $1.62 \mathrm{E}+03$ \\
\hline
\end{tabular}

\begin{tabular}{|c|ccccccc|}
$\mathrm{i}$ & $\mathrm{nu}$ & erl2 & ratiol2 & ergrad & ratiograd & ener & ratioener \\
\hline 1 & 1482 & $2.92 \mathrm{E}-03$ & - & $1.79 \mathrm{E}-01$ & - & $1.78 \mathrm{E}-01$ & - \\
2 & 3960 & $1.38 \mathrm{E}-03$ & $2.29 \mathrm{E}+00$ & $1.22 \mathrm{E}-01$ & $1.18 \mathrm{E}+00$ & $1.21 \mathrm{E}-01$ & $1.16 \mathrm{E}+00$ \\
3 & 9229 & $7.45 \mathrm{E}-04$ & $2.19 \mathrm{E}+00$ & $8.57 \mathrm{E}-02$ & $1.25 \mathrm{E}+00$ & $8.56 \mathrm{E}-02$ & $1.24 \mathrm{E}+00$ \\
4 & 21156 & $5.53 \mathrm{E}-04$ & $1.08 \mathrm{E}+00$ & $6.56 \mathrm{E}-02$ & $9.71 \mathrm{E}-01$ & $6.55 \mathrm{E}-02$ & $9.72 \mathrm{E}-01$ \\
5 & 44420 & $3.77 \mathrm{E}-04$ & $1.55 \mathrm{E}+00$ & $5.14 \mathrm{E}-02$ & $9.85 \mathrm{E}-01$ & $5.13 \mathrm{E}-02$ & $9.83 \mathrm{E}-01$ \\
6 & 82335 & $2.44 \mathrm{E}-04$ & $2.11 \mathrm{E}+00$ & $4.18 \mathrm{E}-02$ & $1.01 \mathrm{E}+00$ & $4.17 \mathrm{E}-02$ & $1.01 \mathrm{E}+00$ \\
7 & 145079 & $1.83 \mathrm{E}-04$ & $1.53 \mathrm{E}+00$ & $3.51 \mathrm{E}-02$ & $9.27 \mathrm{E}-01$ & $3.50 \mathrm{E}-02$ & $9.26 \mathrm{E}-01$ \\
\hline
\end{tabular}




\section{Comments}

The linear system (8) to be solved is symmetric and positive: a Conjugate Gradient algorithm has been applied, together with a basic Jacobi preconditioner. The sparsity pattern of the stiffness matrix is not compact, especially for matrix lines corresponding to vertex nodes. The stiffness matrix lines corresponding to cell nodes have $1+n_{f}+n_{s}$ nonzero terms with $n_{f}$ and $n_{v}$ the number of faces and vertices of the considered cell; for a tetrahedra $1+n_{f}+n_{v}=9$. The maximum principle is not fulfilled by $D D F V$ schemes. In practice it has been violated only once for test one on Voronoï meshes and more significantly on test 3. Meanwhile no oscillation phenomena are observed. Expected order 2 convergence on erl 2 is observed for all tests excepted test 2. Order 1 convergence is observed for ergrad and ener on all tests.

\section{References}

1. Andreianov, B., Bendahmane, M., Karlsen, K.H.: A gradient reconstruction formula for finite volume schemes and discrete duality. Proceedings of FVCA5 (2008)

2. Andreianov, B., Bendahmane, M., Karlsen, K.H.: Discrete duality finite volume schemes for doubly nonlinear degenerate hyperbolic-parabolic equations. J. Hyperbolic Differ. Equ. 7(1), 1-67 (2010)

3. Coudière, Y., Hubert, F.: A 3d discrete duality finite volume method for nonlinear elliptic equation. HAL Preprint URL http://hal.archives-ouvertes.fr/docs/00/ $45 / 68 / 37 / \mathrm{PDF} / \mathrm{ddfv} 3 \mathrm{~d}$.pdf

4. Coudière, Y., Hubert, F.: A $3 \mathrm{~d}$ duality finite volume method for nonlinear elliptic equations. Proceedings of Algoritmy 2009 pp. 51-60 (2009)

5. Coudiere, Y., Pierre, C., Rousseau, O., Turpault, R.: 2D/3D DDFV scheme for anisotropicheterogeneous elliptic equations, application to electrograms simulation from medical data. Int. J. Finite Volumes (2009)

6. Coudière, Y., Vila, J.P., Villedieu, P.: Convergence rate of a finite volume scheme for a two dimensional convection-diffusion problem. M2AN 33(3), 493-516 (1999)

7. Delcourte, S., Domelevo, K., Omnès, P.: Discrete-duality finite volume method for second order elliptic problems. Proceedings of FVCA4 pp. 447-458 (2005)

8. Domelevo, K., Omnes, P.: A finite volume method for the Laplace equation on almost arbitrary two-dimensional grids. M2AN Math. Model. Numer. Anal. 39(6), 1203-1249 (2005)

9. Hermeline, F.: Une méthode de volumes finis pour les équations elliptiques du second ordre. C. R. Acad. Sci. 326(12), 1433-1436 (1998)

10. Hermeline, F.: A finite volume method for the approximation of diffusion operators on distorted meshes. J. Comput. Phys. 160(2), 481-499 (2000)

11. Hermeline, F.: Approximation of 2-D and 3-D diffusion operators with variable full tensor coefficients on arbitrary meshes. Comput. Methods Appl. Mech. Engrg. 196(21-24), 24972526 (2007)

12. Hermeline, F.: A finite volume method for approximating 3D diffusion operators on general meshes. Comput. Meth. Appl. Mech. Engrg. (2009)

13. Jinyun, Y.: Symmetric gaussian quadrature formulae for tetrahedronal regions. Computer Methods in Applied Mechanics and Engineering (1981)

14. Nicolaides, R.: Direct discretization of planar div-curl problems. SIAM J. Numer. Anal. 29(1), 32-56 (1992)

15. Pierre, C.: Modelling and simulating the electrical activity of the heart embedded in the torso, numerical analysis and finite volumes methods. . PhD Thesis, Université de Nantes (2005)

The paper is in final form and no similar paper has been or is being submitted elsewhere. 